\title{
ROTEIRO DE VARIAÇÕES \\ ENTREVISTA COM MANUEL DE FREITAS
}

1. Para uma relação dos títulos publicados por Manuel de Freitas, sugerimos que se consulte $o$ verbete dedicado ao escritor Wikipedia: http://pt wikipedia org/ wiki/Manuel_de_Freitas
Manuel de Freitas (Vale de Santarém, Portugal, 1972) vive desde 1990 em Lisboa. Poeta, ensaísta, tradutor e antologista, também colabora regularmente em várias publicações com artigos de crítica literária. Dirige, com a poeta Inês Dias, a editora Averno (http://editora-averno.blogspot.pt/) e as revistas Cão Celeste (http://ocaoceleste.blogspot.com.br/) e Telhados de Vidro. De 2000 até o presente, publicou mais de 40 livros $^{1}$ de poesias, antologias e ensaios, dentre os quais se destacam Poetas sem qualidades (2002), A Última Porta (2010), Uma espécie de crime: Apresentação do Rosto de Herberto Helder (2001), Me, Myself and I - Autobiografia e imobilidade na poesia de Al Berto (2005) e Pedacinhos de Ossos (2012).
* clabrac1980@gmail.com Doutorando em Teoria da Literatura e Literatura Comparada - FALE/UFMG

** sergioflub@gmail.com

Doutorando em Teoria da Literatura e Literatura Comparada - FALE/UFMG.

A ideia de entrevistá-lo surgiu quando conversávamos sobre escritores que se dedicam à crítica literária, de modo a problematizar os protocolos de leitura e escrita que regem o texto crítico. Alguns meses antes de termos esta conversa, na busca por algumas das obras do Manuel nas livrarias lisboetas, o Sérgio acabou por chegar à livraria Paralelo W, onde teve o prazer de conhecer e conversar com o escritor. Tal encontro resultou em uma maior aproximação com os textos do poeta, além de abrir a possibilidade de dialogar com um dos grandes nomes da literatura portuguesa contemporânea na presente edição de nossa revista. 
Depois de passarmos algumas tardes lendo ensaios e poemas de Manuel de Freitas, escrevemos um e-mail ao pueto que, gentilmente, concordou em conceder a entrevista. $\mathrm{O}$ resultado da troca de e-mails é este breve "roteiro de variações”, no qual Manuel discorre acerca da recepção de sua obra no Brasil, da relação do poeta com a tradição e o contemporâneo, além, claro, das possibilidades da crítica e da poesia - com ou sem qualidades.
01. ALGUNS DE SEUS POEMAS, CERTA VEZ, FORAM LIDOS COMO TRACCOS DE UM “DETALHADO ROTEIRO OBSESSIVO, COM VARIAÇÕES MÍNIMAS". ${ }^{2}$ SE AQUI PUDÉSSEMOS LER QUE AS "VARIAÇÕES MÍNIMAS" SE ENCONTRAM NOS MODOS ESPECÍFICOS DE CRIAÇÃO, ARRISCARÍAMOS TAMBÉM DIZER QUE É JUSTAMENTE NA DIFERENÇA RESIDUAL DESSES MODOS QUE SE GUARDA A POTÊNCIA DE CRIAR.

EM BOA PARTE DE SEU TRABALHO COMO ENSAÍSTA, ANTOLOGISTA, TRADUTOR, CRÍTICO E EDITOR PERCEBEMOS - DE OUTRO MODO TAMBÉM SILENCIOSO E PERTURBADOR - UM GESTO OUE PARECE PERMEAR A SUA POESIA.

COMO VOCÊ VÊ - EM SUA OBRA - ESSE PRECIPITAR-SE DA POESIA EM OUTRAS FORMAS DE CRIAÇÃO CONSIDERADAS, À PRIMEIRA VISTA, EXTRAPOÉTICAS?

MF - Agradam-me, e parecem-me extremamente pertinentes quanto àquilo que escrevo, as expressões «roteiro» («obsessivo», reconheço) e «variações» («mínimas», em rigor). Mas as referidas variações, num sentido quase musical, têm como pano de fundo roteiros bastante distintos, que tanto podem ser o itinerário de tabernas lisboetas, entretanto desaparecidas, como a evocação de afectos particulares ou a enumeração de canções ou concertos específicos. Pode ainda tratar-se de um roteiro quase estritamente geográfico, uma vez que alguns dos meus livros são consequência directa de viagens. Em qualquer dos casos, tudo resulta de uma certa flânerie em que planos diversos talvez acabem por se fundir num mesmo olhar, que é, inevitavelmente, o meu. Os
2. Conforme Pedro Mexia, também poeta e crítico literário, no artigo "Poetas sem qualidades e poemas sem qualidades", publicado no Diário de notícias em setembro de 2004. Disponível em versão virtual no link: http:// www aspx?content id =593058. 
3. FREITAS, Manuel de. “O tempo dos puetas". In: Pedacinhos de ossos. Lisboa: Averno, 2012, p. 155 poemas acontecem(-me) porque aconteceram coisas (uma viagem, um encontro, uma memória subitamente desperta). Nunca estive sentado a uma mesa, diante de uma folha em branco, à espera de que surgissem versos.

Admito que, em certos aspectos, a minha «atitude» poética possa contaminar outros registos e actividades, sobretudo enquanto antologiador e ensaísta. Já enquanto crítico, procuro observar a máxima isenção, evitando que a voz do poeta se intrometa. No que respeita à edição, e em particular à Averno, todos os riscos e decisões são, desde o início, partilhados com a Inês Dias. Seja como for, considero que estas outras formas de criação podem e devem ser poéticas, em sentido lato.

02. “AO CONTRÁRIO DO QUE PARECE SUCEDER COM OS ROMANCISTAS"3 - COMO VOCÊ COLOCA -, OS POETAS OCUPAM UMA ZONA DE ENFRENTAMENTO ONDE ESTÁ EM JOGO O DAR-SE-A-VER DE UM “AGORA" OUE O PRESENTE TEM TORNADO CADA VEZ MAIS ILEGÍVEL E INESCREVÍVEL.

NESSES TERMOS, PODERIA SE FALAR QUE - POR UM VIÉS DISCURSIVO - A MESMA ANALOGIA ESTABELECIDA A PARTIR DA BIPOLARIDADE QUALITATIVO/QUANTITATIVO SE ESTENDE, DE ALGUM MODO, À OPOSIÇÃO POETA/ROMANCISTA? COMO VOCÊ COMPREENDE ESSA RELAÇÃO ENTRE PROSA E POESIA EM MEIO A UMA CONTEMPORANEIDADE QUE TAMBÉM DEVE APRENDER A SUPERAR OS MURAMENTOS DISCURSIVOS?

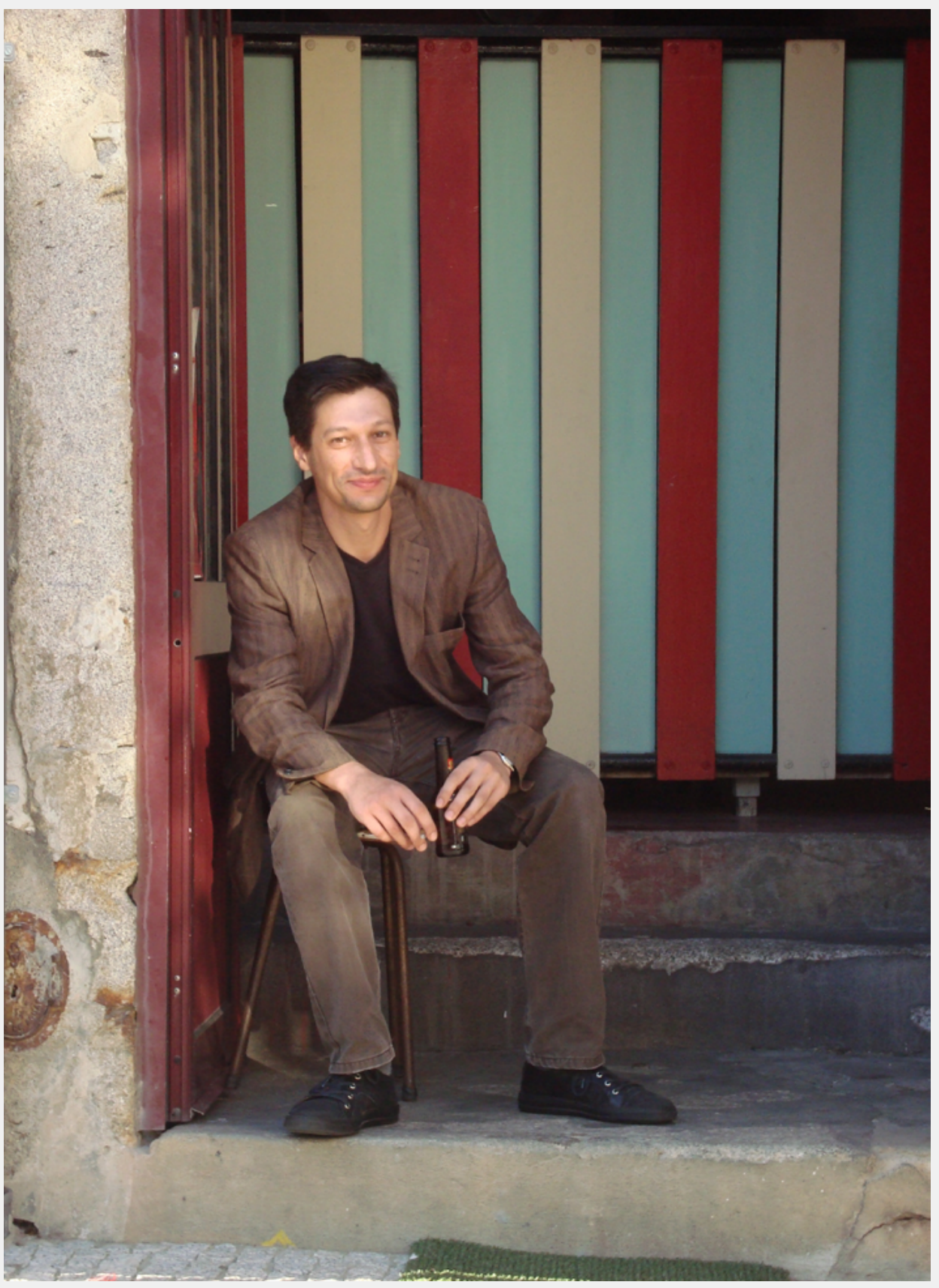


MF - Há várias décadas e por diversas vozes se tem afirmado que a poesia é, em Portugal, «a mais alta afirmação literária». Semelhante constatação mantém-se, quanto a mim, válida. $\mathrm{O}$ que não impede que tenhamos excelentes romancistas. $\mathrm{O}$ grande problema do romance talvez resida no facto de se ter tornado uma actividade extremamente lucrativa, sendo cada vez mais os prosadores que acatam uma lógica mercantil, que os sujeita a contratos, prazos e à mediação nefasta (para literatura, entenda-se) de agentes literários. Viver da escrita pode até ser muito confortável, mas obriga os autores a um calendário preciso, a gestos regulares de exposição, a ferozes tentativas de exportação. Muitos dos chamados «romances» que hoje se publicam em Portugal são meros produtos resultantes de predatórios esquemas editoriais.

A poesia está nos antípodas destes mecanismos de marketing cada vez mais rudes e eficazes. Acontece quando tem de acontecer, em tiragens geralmente restritas. É uma sorte, para o poeta, saber que nunca vai enriquecer pelo facto de publicar livros. Sob outro ponto de vista, não deixa de ser uma tremenda injustiça.

Até pelas pressões a que está sujeito, o romancista está quase sempre do lado de quantitativo, enquanto o poeta exigente procura, de facto, o qualitativo; de preferência um qualitativo que não exclua a participação - pela palavra - no tempo histórico e biográfico que lhe foi dado viver. Para não parecer demasiado generalista no que disse dos prosadores portugueses contemporâneos, gostaria de evocar duas excepções que têm vindo, justamente, a questionar a «oposição poeta/romancista»: Maria Velho da Costa e Rui Nunes.

03. FALAR DE UMA "IDEIA DA PROSA" - COMO BEM O OUISERAM PENSADORES COMO WALTER BENJAMIN E GIORGIO AGAMBEN NÃO IMPLICA EM FALAR DA PROSA PROPRIAMENTE, SE BEM QUE DE UMA OPERAÇÃO OUE CONSISTE EM COMPOR UMA "IDEIA" DE PENSAMENTO CUJA FÓRMULA É REGIDA PELA POTÊNCIA DE PROFANAR O VERSO. COMO NAS IMAGENS DAS "PROSAS MIÚDAS" QUE, EM KAFKA, TOCAM SILENCIOSAMENTE O OUE PODEMOS CHAMAR DE PENSAMENTO, AQUI TAMBÉM É ABERTA A POSSIBILIDADE DE SE PENSAR NUMA "IDEIA" DE CRÍTICA.

SE, ASSIM, À POESIA CABE A RESPONSABILIDADE ESTÉTICA DE UM DAR-SE-A-VER DO PRESENTE, CONCORDA QUE A RESPONSABILIDADE CRÍTICA DEVE ESTAR PARA AQUILO QUE RESTA DE POESIA EM SEU DISCURSO? PARA ESSE CASO, PODERIA SE DIZER OUE À IDEIA DE UMA POESIA "SEM QUALIDADES" CORRESPONDERIA A POSSIBILIDADE DE UMA CRÍTICA "SEM OUALIDADES"?

MF - «Profanar o verso» é uma ideia interessante. Desde o modernismo, e da irrupção das vanguardas a ele directa ou indirectamente associadas, que a poesia teve de se confrontar com a perda de auréola anunciada por Baudelaire e longamente comentada por Benjamin. Essa dessacralização da poesia, que é simultaneamente religiosa e comercial, não me parece um fenómeno lamentável. Pelo contrário, ao descer dos vários pedestais que historicamente lhe foram 
concedidos, o poeta passou a ter como único juiz os seus leitores, por poucos que sejam. Concomitantemente, e porque a história assim o quis, pôde furtar-se às regras económicas que norteiam o romance e as artes plásticas, transformando quase tudo num mercado assumido e hegemónico.

A ideia de uma «poesia sem qualidades», onde o referente musiliano é (ou deveria ser) óbvio, assenta, antes de mais, numa inadequação entre as qualidades evidentes de certos poetas e a receptividade do público contemporâneo, inclusive em termos numéricos. Pensando no panorama português, se poetas como Ana Paula Inácio, José Miguel Silva ou Rui Pires Cabral dificilmente vendem 300 exemplares de cada um dos seus livros, isso significa que existe de facto um acentuado divórcio entre a melhor poesia e o grande público. Estatisticamente falando, «a poesia não interessa» (como já advertira T.S. Eliot). Mas há um tempo mais longo - «o que fica, os poetas o fundam», no dizer claro de Hölderlin - que provavelmente virá a fazer justiça a estes e outros nomes. Não creio, de resto, que nenhum dos poetas portugueses mencionados esteja muito preocupado com a posteridade.

Sob um prisma bastante diferente, torna-se quase pleonástico falar de uma crítica «sem qualidades». Em Portugal, pelo menos, a crítica encontra-se claramente ameaçada; cedeu lugar a uma divulgação sumária, subserviente de fortes pressões editoriais. $\mathrm{Na}$ imprensa, o espaço dedicado à literatura diminuiu drasticamente nos últimos dez anos. É a própria possibilidade da crítica - com ou sem qualidades que se vê agora posta em causa.

04. VOCÊ AFIRMA, NUM DE SEUS ESTUDOS, QUE A “POESIA É UMA REALIDADE HISTÓRICA". ${ }^{4}$ DE OUE MODO COMPREENDE OUE TAL CONCEPÇÃO - EM SUA EXPERIÊNCIA - PODE SER CONJUGADA ÀQUELA QUE VOCÊ DEFINE POR "RESTO"?

MF - A poesia é uma realidade histórica no exacto sentido em que cada poeta deve ter um conhecimento, o mais alargado possível, das vozes todas que o precederam; mas é-o também no sentido em que o poeta faz parte de um tempo concreto, ao qual tem de responder. Mesmo tentativas admiráveis de acronia (Hölderlin, Saint-John Perse, algum Herberto Helder) foram motivadas por um tempo histórico preciso. A questão do «resto» (ou dos «restos») prende-se com a secundarização a que a poesia tem sido votada. Sendo o que «não interessa» (comercial ou estatisticamente), a poesia é, no entanto, uma energia imparável. Assiste-lhe, ao contrário de outros géneros literários, uma imensa desrazão - e por isso continua viva e actuante.

05. EM PHOTOMATON \& VOX, HERBERTO HELDER PONTUOU OUE O “OFUSCANTE PODER DA ESCRITA É OUE ELA POSSUI UMA CAPACIDADE DE PERSUASÃO E VIOLENTAÇÃO DE OUE A COISA REAL SE ENCONTRA SUBTRAÍDA". ${ }^{5}$ CONDUZAMOS TAL PERSPECTIVA ÀS FORMAS DE REFLEXÃO ACERCA DA RELAÇÃO DA POESIA COM A CONTEMPORANEIDADE.
4. FREITAS, Manuel de. “O tempo dos puetas". In: Pedacinhos de ossos. Lisboa: Averno, 2012, p.159.

5ELDER, Herberto. Photomaton \& Vox. Lisboa: Assírio \& Alvim, 1987, p.56. 
6. Negrita-se, aqui, o gesto notado em grande parte da obra poética mas também nos lugares de antologista (A perspectiva da porta) e de ensaísta (Me, myself and I e Pedacinhos de ossos).
COMO VOCÊ DEFINIRIA, PARA ESSE CASO, O LUGAR DA POESIA HOJE A PARTIR DO DESCOMPASSO NOTADO ENTRE A VIOLÊNCIA POÉTICA E A VIOLÊNCIA COMO IRRUPÇÃO DO EXTERIOR, OU SEJA AOUELA EM QUE A PERSUASÃO, DESVENCILHADA DA VIOLÊNCIA SÓ SE TORNA POSSÍVEL ENOUANTO ATO DE VIOLÊNCIA?

MF - Não consigo subscrever esse deslumbramento verbal presente na citação de Herberto Helder. Um poema faz-se especificamente de palavras, tal como uma sonata se faz de notas. Alguns resultam, outros não. A violência exterio (a do chamado «real», que dura pouco mas existe) será sem pre maior do que qualquer violência poética. A poesia não tem de ser violenta, mas pode e deve responder à violência de tudo o que a rodeia. Celan - ao contrário de Artaud ou de Michaux - não é propriamente um poeta violento. Mas poucos terão «respondido» de forma tão exemplar à barbárie europeia do século XX. Hoje, como é sabido, assistimos formas mais subtis e sofisticadas de barbárie, a uma espécie de burocratização do horror. É contra isso, precisamente, que se têm insurgido alguns poetas recentes (por exemplo Pádua Fernandes e Rosa Maria Martelo).

06. PODERIA A MORTE, COMO ELEMENTO PULSANTE EM SUA OBRA ${ }^{5}$ NOS CONDUZIR À POSSIBILIDADE DE SE PENSAR NA VIOLÊNCIA POÉTICA EM SEU TRABALHO? SE ESSE FOR CASO, O OUE DIZER ACERCA DA TENDÊNCIA DA POESIA CONTEMPORÂNEA DEF NIDA PELO TERMO TANATOPOÉTICA?
MF - Volto a encarar com algumas reservas o termo «violência poética», que de modo nenhum reivindico. Quanto à morte, ela esteve sempre aqui. Vai acontecer, é um processo há muito iniciado. Costumo pensar (e talvez Cioran concordasse) que a melhor literatura é sempre uma actualização do Eclesiastes. Mudam o enredo, o lugar, o nome - mas o fim será sempre o mesmo. A meio do caminho, encontramos Montaigne ou Pascal. Daí, talvez, não fazer para mim muito sentido o termo «tanatopoética». Parece-me implícito em cada poema, ao longo das gerações, a asserção «eu, que vou morrer, quis dizer isto».

07. ESGOTADANO BRASIL, AANTOLOGIADO PROJETOPORTUGAL, $0^{7}$ ORGANIZADA E SELECIONADA POR LUIZ MAFFEI, SINALIZA BEM O PRIMEIRO CONTATO DOS BRASILEIROS COM A SUA POESIA. COMO VOCÊ ENXERGA ESSA RECEPÇÃO? VOCÊ MANTÉM DIÁLOGOS COM PESOUISADORES, PENSADORES E/OU POETAS BRASILEIROS? OUAL É SUA RELAÇÃO COM A LITERATURA BRASILEIRA, TANTO A DO PASSADO COMO A DE HOJE?

MF - Não fiz as contas, mas é provável que haja mais estudiosos da minha poesia no Brasil do que em Portugal, o que também é válido para Rui Pires Cabral. Aqui - e isto é igualmente válido para ambos - mantemos uma tranquila invisibilidade. Com algum reconhecimento, claro, e os tais (por vezes) 300 leitores que nos fazem acreditar um pouco mais no que fazemos.
7. FREITAS, Manuel. Portugal, 0 - 1 Rio de Janeiro: Oficina Raquel, 2007. 
8. BORGES, Jorge Luis. Kafka e seus precursores (1951). In: Outras inquisiçôes (1952). Obras completas. vol. 2. São Paulo: Globo, 1999, p. 96-98.
Tenho algum contacto com pesquisadores e poetas brasileiros, seja por e-mail seja por se dirigirem à livraria Paralelo W, em Lisboa, de que faço parte. A literatura brasileira sempre me interessou, de Machado de Assis a Clarice Lispector ou Rubem Fonseca. No que se refere à poesia, e pensando em autores vivos, destacaria os seguintes nomes: Eucana Ferraz, Fabiano Calixto, Fabio Weintraub, Ferreira Gullar e Pádua Fernandes. Lamento já não poder acrescentar a esta lista Manoel de Barros, recentemente falecido.

08. POR FIM, VOCÊ MENCIONA, NA QUARTA QUESTÃO DESTA ENTREVISTA, QUE “CADA POETA DEVE TER UM CONHECIMENTO, O MAIS ALARGADO POSSÍVEL, DAS VOZES TODAS OUE O PRECEDERAM". A PARTIR DESTA CONSIDERACCÃO, COMO SUA LINGUAGEM (CRÍTICA, ENSAÍSTICA OU POÉTICA) SE RELACIONA COM AS OBRAS DE AL BERTO E HERBERT HELDER? VOCÊ OS TEM POR PRECURSORES, NA ACEPÇÃO QUE JORGE LUIS BORGES PROPÕE EM “KAFKA E SEUS PRECURSORES", ${ }^{8}$ DE QUE CADA ESCRITOR, NA CONDIÇÃO DE LEITOR, INTERVEM NAS CONDIÇÕES DE ESCUTA E LEITURA DAS VOZES OUE O ANTECEDEM, CRIANDO, ASSIM, UMA CONSTELAÇÃO LITERÁRIA PARA RESPONDER ÀS QUESTÕES DA ÉPOCA NA OUAL SE INSCREVE?

MF - Neste ponto, talvez seja útil recorrer a factos biográficos bastante concretos. Por mero acaso, Al Berto foi o primeiro poeta contemporâneo que eu li na íntegra (pouco depois da reunião da sua obra em $O$ Medo, Lisboa, Contexto, 1987). Eu teria dezasseis anos, muito poucas leituras poéticas, e fiquei naturalmente deslumbrado com aquela escrita torrencial, mesmo (ou sobretudo) no que então me parecia ter de «incorrecta». Havia, além do mais, fortes afinidades extra-literárias (Velvet Underground, Joy Division, etc.) entre aquela escrita intensamente urbana e a minha vivência musical de adolescente provinciano. Com o passar dos anos, relativizei um pouco a importância literária de $\mathrm{Al}$ Berto, até por haver na sua geração poetas portugueses de primeira grandeza, mas tratou-se, para mim, de um encontro marcante.

Por essa mesma altura, também por acaso, não se encontrava disponível no mercado a obra poética reunida de Herberto Helder. Tive de esperar por 1990 para poder ler, enfim, Poesia Toda (Lisboa, Assírio \& Alvim). Mas aos dezoito anos, creio, já eu sofrera na pele as principais influências e resistências; a poesia de Herberto Helder não teve, portanto, qualquer efeito de contaminação assinalável. Admiro-a, claro, mas o meu grande embate com a escrita helderiana passa pela descoberta, ainda na adolescência, de Os Passos em Volta e de Photomaton $\mathcal{E}$ Vox. È nesses dois livros - e, anos mais tarde, em Servidões (Lisboa, Assírio \& Alvim, 2013) que me sinto realmente «próximo» de Herberto Helder, com a devida humildade. Enquanto ensaísta, julgo ter apre(e) ndido muito mais com o desassombro anti-académico de Photomaton \& Vox do que com Barthes ou Derrida.

A interessante reflexão de Borges sobre o modo como cada escritor cria os seus precursores tornou-se, por exemplo em 
Harold Bloom, um fastidioso delírio freudiano. Não me parece que essas questões de genealogia possam ser resolvidas de ânimo leve, por mais denso que seja o aparelho teórico utilizado. Existe, em última análise, uma linhagem electiva sugerida por cada poeta e variável ao longo da sua obra. Mas essa linhagem, na maior parte das vezes, não se deixa reduzir a efeitos de «influência» nem a gestos edipianos. Pela minha parte, gostaria de frequentar um café onde pudesse encontrar François Villon, Camilo Pessanha, Fernando Assis Pacheco, Jaime Gil de Biedma, Luiza Neto Jorge ou Carlos de Oliveira. 